OPEN ACCESS

Edited by:

Andreas Recke,

University of Lübeck, Germany

Reviewed by:

André Rolim Baby, University of São Paulo, Brazi

Hasan Onur Dikmen,

University of Lübeck, Germany

*Correspondence:

Alvise Sernicola

alvise.sernicola@me.com

†These authors have contributed equally to this work and share first authorship

Specialty section:

This article was submitted to Dermatology,

a section of the journal

Frontiers in Medicine

Received: 17 October 2021 Accepted: 03 December 2021 Published: 20 December 2021

Citation:

Sernicola A, Cama E, Pelizzo MG,

Tessarolo E, Nicolli A, Viero G and Alaibac M (2021) In vitro Assessment

of Solar Filters for Erythropoietic Protoporphyria in the Action Spectrum of Protoporphyrin IX.

Front. Med. 8:796884.

doi: 10.3389/fmed.2021.796884

\section{In vitro Assessment of Solar Filters for Erythropoietic Protoporphyria in the Action Spectrum of Protoporphyrin IX}

\author{
Alvise Sernicola ${ }^{1 * t}$, Elena Cama ${ }^{1+}$, Maria Guglielmina Pelizzo ${ }^{2,3}$, Enrico Tessarolo $^{3}$, \\ Annamaria Nicolli ${ }^{4}$, Giulia Viero ${ }^{1}$ and Mauro Alaibac ${ }^{1}$ \\ ${ }^{1}$ Dermatology Unit, Department of Medicine (DIMED), University of Padova, Padua, Italy, ${ }^{2}$ Department of Information \\ Engineering, University of Padova, Padua, Italy, ${ }^{3}$ Institute for Photonics and Nanotechnologies, National Research Council of \\ Italy, Padua, Italy, ${ }^{4}$ Department of Cardiac, Thoracic, Vascular Sciences and Public Health (DCTV), University of Padova, \\ Padua, Italy
}

Introduction: Subjects with erythropoietic protoporphyria rely on broad-spectrum sunscreens with high sun protection factor, which is not informative on efficacy in the absorption spectrum of protoporphyrin IX, spanning visible radiation and peaking around $408 \mathrm{~nm}$. Photoactivation of protoporphyrin IX is responsible for painful skin photosensitivity in erythropoietic protoporphyria.

The authors assessed the protective efficacy of six sunscreens in vitro in the absorption spectrum of protoporphyrin IX.

Method: Transmittance measurements were performed in the $300-850 \mathrm{~nm}$ wavelengths on samples of six photoprotective products applied to polymethyl methacrylate plates. Porphyrin protection factor was calculated in the $300-700 \mathrm{~nm}$ region to provide a measurement for the efficacy of each product based on the action spectrum of protoporphyrin IX.

Results: Product A showed the highest porphyrin protection factor among tested products with a median value of 4.22. Product $A$ is a sunscreen containing organic filters, titanium dioxide and synthetic iron oxides, pigmentary grade active ingredients that absorb visible radiation. Other products showed inefficient protection in the visible, with transmittance between 75 and $95 \%$ at $500 \mathrm{~nm}$. The low porphyrin protection factor of inorganic filter product B was attributed to particle micronization, as declared by the manufacturer.

Conclusion: Adding porphyrin protection factor to sunscreen labeling could help patients with erythropoietic protoporphyria and other photosensitivity disorders identify products tailored on their specific needs. The development of sunscreens providing protection from visible radiation and excellent cosmetical tolerability could improve the lifestyle of patients with erythropoietic protoporphyria.

Keywords: erythropoietic protoporphyria, photoprotection, protoporphyrin IX, sunscreen, cutaneous porphyria, Photodermatosis 


\section{INTRODUCTION}

Erythropoietic protoporphyria (EPP) is a cutaneous porphyria resulting from loss-of-function mutations in the ferrochelatase gene $(F E C H)$ with autosomal recessive Mendelian inheritance (1). Alternatively, gain-of-function mutations in aminolevulinic acid synthase gene (ALAS2) are responsible for the closely related phenotype termed X-linked protoporphyria (XLP) with X-linked inheritance (2). Additional mutations have been reported (3) and EPP can also develop de novo in the context of myeloproliferative disorders $(4,5)$. Most commonly, EPP phenotype results from the inheritance of a common hypomorphic FECH variant, IVS3-48T/C, together with a loss-of-function allele of the same gene (6). This leads to insufficient activity of the FECH enzyme which inserts iron or zinc in the protoporphyrin IX ring, finalizing heme formation in the inner mitochondrial membrane (1). The result is excessive metal-free protoporphyrin accumulation occurring in plasma and erythrocytes. Metal-free protoporphyrin diffuses to plasma from erythrocytes, where it is bound to hemoglobin and released following light irradiation, and directly from reticulocytes in the bone marrow (7-9). Metal-free protoporphyrin accumulates in plasma contributing to photosensitivity and is bound to albumin, which provides the only excretion pathway for this water-insoluble porphyrin through the liver (9-11). Hydrophobic protoporphyrin deposits in lipidic layers of cell membranes (12) in the skin, where acute painful non-blistering photosensitivity develops. Liver damage is an uncommon finding potentially complicating EPP in as few as $5 \%$ of cases $(13,14)$. However, the risk of gallstones containing water-insoluble protoporphyrin is increased to up to $8 \%$ of patients (14). Excluding patients who develop protoporphyriarelated hepatopathy, the risk for which cannot be accurately predicted (15), life expectancy in EPP is not shortened compared to the general population. This leads to lasting impairment on employment and lifestyle due to the need to avoid sunlight. Onset of photosensitivity in EPP occurs early in childhood, at an average before the age of four (16) and with no difference between sexes. However, diagnosis is commonly delayed to an average of 13 years from the first symptoms (16), during which undiagnosed children and adults endure unexplained pain and withdrawal from daily social activities. Following exposure to sunlight or fluorescent light sources, severe skin pain with or without signs of erythema, edema, or blanching, develops acutely after a median of $20 \mathrm{~min}$ and resolves after a median of 3 days (14) leaving little to no residual skin damage. Chronic changes may affect the skin on the knuckles and back of hands and on the face in patients subject to repeated light exposure (17-19). Physical findings are related to individual differences in pigmentation, degree of sun exposure and reportedly to a priming phenomenon (14). The severity of symptoms is also dependent on the level of erythrocyte protoporphyrin, for which no corrective intervention is available. Protection from sunlight exposure is the main strategy to manage the symptoms of EPP and to limit impairment of educational and employment opportunities in these patients. Therapies to increase light tolerance include subcutaneous afamelanotide and oral beta-carotene. Synthetic alpha-melanocyte stimulating hormone afamelanotide has been available in Europe since 2014 as a $16 \mathrm{mg}$ subcutaneous implant administered every 2 months 3 times a year to adult patients (20), and effectively improves sunlight tolerance allowing patients to engage in activities that would previously be avoided (21). However, evidence supporting its use in pediatric patients is lacking, as is safety data in pregnancy or in liver and kidney disease (22). Use of beta-carotene proved beneficial in some patients $(23,24)$; however, overall evidence is inadequate and results of a randomized controlled trial showed no improvement in light tolerance compared to placebo (25). Subjects with EPP require photoprotection in the UV-A and visible light regions, where the absorbance spectrum of protoporphyrin lies (26). The efficacy of commercially available sunscreens is commonly assessed in the UV-B and UV-A bandwidth; however, their protective effect against visible light is generally not significant and poorly characterized. A photoprotective index named porphyrin protection factor $(\mathrm{PPF})$ was recently introduced to measure the in vitro efficacy of photoprotective products based on the absorbance of protoporphyrin IX in the $300-450 \mathrm{~nm}$ wavelength region (27). As current commercial sunscreens do not significantly absorb in this region, specific effective topical photoprotection is a current area of unmet need in EPP.

The present study aimed at assessing the in vitro protective efficacy of six sunscreens by calculating PPF, as previously described in the $300-450 \mathrm{~nm}$ region and extended to the 300$700 \mathrm{~nm}$ wavelengths to include different absorption peaks of protoporphyrin IX: an intense Soret band centered around $406 \mathrm{~nm}$ and four weaker $\mathrm{Q}$ bands in the visible range (26).

\section{METHOD}

\section{Tested Photoprotective Products}

Six sunscreens were independently selected by the investigators among commercially available products labeled with high SPF and wide-spectrum protection from radiations including UV-A (Table 1).

\section{In vitro Substrates}

Samples were placed on polymethyl methacrylate (PMMA) square plates (Schönberg GmBH \& Co, Hamburg, Germany) sized $50 \times 50 \times 2.5 \mathrm{~mm}$ and with a rugosity around $6 \mu \mathrm{m}$. PMMA plates are appropriate substrates for in vitro assessments of UV-A blockers according to COLIPA (European Cosmetics Trade Association) guidelines (28) and are used in previous published studies (27). Five samples of each product were each applied to the upper surface of a PMMA plate using a positive-displacement dispenser (Multipette; Eppendorf AG, Hamburg, Germany). Samples were weighted using a precision scale $(\Delta g= \pm 0.1 \mathrm{mg})$ to assess correct application rate and consistent distribution among samples with a surface density of $1 \mathrm{mg} / \mathrm{cm}^{2}$. Amounts of $1 \mathrm{mg} / \mathrm{cm}^{2}$ applied on PMMA plates showed good correlation between in vitro and in vivo SPF in previous studies (29). For the present investigation, a single rate of application was chosen to allow comparison between the absorbance curves of different samples in vitro. According to the authors' previous experimental results obtained for PMMA plates with $1 \mathrm{mg} / \mathrm{cm}^{2}$ of product application, the correlation 


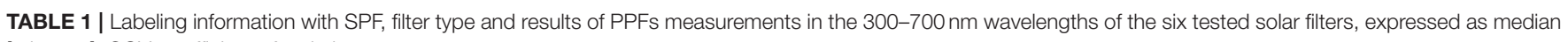
[min;max]. COV, coefficient of variation.

\begin{tabular}{|c|c|c|c|}
\hline Product (label SPF) & Principal active components & PPF 300-700 nm & cov \\
\hline A $(50+)$ & $\begin{array}{l}\text { - Octocrylene, } \\
\text { - Methylene bis-benzotriazolyl tetramethylbutylphenol [nano], } \\
\text { - Butyl methoxydibenzoylmethane, } \\
\text { - Titanium dioxide (ci 77891), } \\
\text { - Bis-ethylhexyloxyphenol methoxyphenyl triazine, } \\
\text { - Iron oxides (Cl 77492, 77491, 77499). }\end{array}$ & $4.22[3.34 ; 4.78]$ & 0.1226 \\
\hline B (30) & $\begin{array}{l}\text { - Zinc oxide (nano), } \\
\text { - Titanium dioxide (nano). }\end{array}$ & $1.73[1.66 ; 1.75]$ & 0.0270 \\
\hline$C(100+)$ & $\begin{array}{l}\text { - Ethylhexyl methoxycinnamate, } \\
\text { - Diethylamino hydroxybenzoyl hexyl benzoate, } \\
\text { - Octocrylene, } \\
\text { - Ethylhexyl triazone, } \\
\text { - Titanium dioxide (nano), } \\
\text { - Bis-ethylhexyloxyphenol methoxyphenyl triazine. }\end{array}$ & $1.86[1.76 ; 1.92]$ & 0.0365 \\
\hline D (50+) & $\begin{array}{l}\text { - Ethylhexyl methoxycinnamate, } \\
\text { - Methylene bis-benzotriazolyl tetramethylbutylphenol (nano), } \\
\text { - Bis-ethylhexyloxyphenol methoxyphenyl triazine, } \\
\text { - Ethylhexyl salicylate, } \\
\text { - Diethylamino hydroxybenzoyl hexyl benzoate. }\end{array}$ & $1.82[1.73 ; 1.84]$ & 0.0259 \\
\hline$E(50+)$ & $\begin{array}{l}\text { - Octocrylene, } \\
\text { - Ethylhexyl salicylate, } \\
\text { - Butyl methoxydibenzoylmethane, } \\
\text { - Ethylhexyl triazone, } \\
\text { - Bis-ethylhexyloxyphenol methoxyphenyl triazine. }\end{array}$ & $1.65[1.61 ; 1.68]$ & 0.0171 \\
\hline$F(50+)$ & $\begin{array}{l}\text { - Bis-ethylhexyloxyphenol methoxyphenyl triazine, } \\
\text { - Ethylhexyl triazone, } \\
\text { - Diethylamino hydroxybenzoyl hexyl benzoate, } \\
\text { - Diethylhexyl butamido triazone. }\end{array}$ & $1.53[1.52 ; 1.59]$ & 0.0190 \\
\hline
\end{tabular}

between in vitro measurements and in vivo SPF does not yield a 1:1 correspondence but can be described with a regression line $(30,31)$. For this reason, evaluation of in vitro SPF values remained beyond the scope of this study.

\section{Transmittance Measurements}

Transmittance measurements were performed in the 300$850 \mathrm{~nm}$ range using an integrating sphere spectrophotometer (Cary 5000; Varian Medical Systems, Inc., Palo Alto, CA, U.S.) with photomultiplier tube R928 (Hamamatsu Photonics K.K., Hamamatsu City, Japan). Single measure statistical error for this equipment is reported around $1 \%$. Transmittance of substrates (T\%) was expressed as percentage of the baseline transmittance of each PMMA plate before application of each sample.

\section{Calculation of in vitro Protection Factor}

In vitro efficacy of each sunscreen was expressed using porphyrin protection factor (PPF), as previously defined in the literature as ratio of two integrals calculated in the spectral range of 300$450 \mathrm{~nm}$ (27) and as modified by the authors in the range of $300-700 \mathrm{~nm}$ to include measurement of protective effect against damage from visible light:

$$
P P F=\int_{\lambda=300}^{\lambda=700} P P(\lambda) I(\lambda) d \lambda / \int_{\lambda=300}^{\lambda=700} P P(\lambda) I(\lambda) 10^{-A(\lambda)} d \lambda
$$

Calculations are based on the absorbance $A(\lambda)$ retrieved by the transmittance value, and on action spectrum $\operatorname{PP}(\lambda)$ of protoporphyrin IX and on the standard solar spectral irradiance $I(\lambda)$ with air mass of $1.5 \mathrm{G}(32)$.

\section{Statistical Analysis}

Analyses were performed using the SAS 9.4 package (SAS Institute Inc., Cary, NC, USA) on Windows. The continuous variable PPF was presented as median and range of the measurements for the substrate of each sample. Comparison of PPF between the six different samples was performed using the Kruskal-Wallis test, a non-parametric test for multiple independent samples. When significance was found from this test, the Dwass-Steel-Critchlow-Fligner test, a two-sided nonparametric procedure, was used to determine which groups were different. Results were considered significant at $p<$ 0.05. Differences between medians estimated using the HodgesLehman statistics were presented as $95 \%$ confidence intervals.

\section{RESULTS}

Product A, a physical barrier cream, resulted in a median PPF value of 4.22 [range $=3.34-4.78$ ], the highest among tested products. In vitro PPFs for the remaining samples are reported in Table 1 (=median [range]). The Kruskal-Wallis test on the six samples showed significance $(p<0.0001)$ and PPFs were 


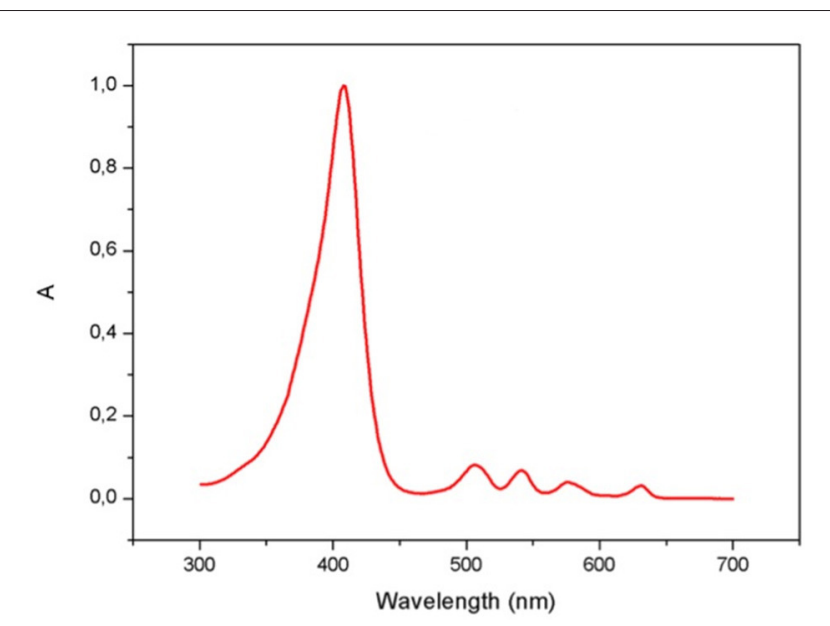

FIGURE 1 | Absorbance (A) spectrum of protoporphyrin IX measured in the range $300-700 \mathrm{~nm}$.

then compared pairwise between products demonstrating a statistically significant difference $(p<0.05)$ between medians of product $A$ and each of the five other samples (95\% confidence interval): vs. product $\mathrm{B}(1.68 ; 3.03)$, vs. C $(1.77 ; 2.84)$, vs. D $(1.61 ; 2.94)$, vs. E $(2.00 ; 2.98)$, vs. F $(1.82 ; 3.19)$.

\section{DISCUSSION}

Porphyrins are photoactive compounds that cause damage to biological molecules, following activation by light and transfer of energy to highly oxidizing oxygen species (12, 33-35). Protoporphyrin IX absorption occurs between 320 and $595 \mathrm{~nm}$ and peaks in the $400-420 \mathrm{~nm}$ wavelength, known as the Soret band for porphyrins, which lies in the visible range close to UVA light (36) (Figure 1). Poor quality of life in EPP patients is related to sunlight avoidance that, though effectively preventing symptoms, restricts recreational and productive activities (37). The appropriate management of this condition must therefore focus on providing strategies to maximize light tolerance and allow engagement in normal daily activities. Topical sunscreens, combined with hats and protective clothing when outdoors and lifestyle adaptations $(38,39)$, are a key photoprotective intervention in EPP.

Commercially available products contain organic and inorganic filters that are well characterized according to their protection from UV-B and UV-A radiation $(40,41)$ but lack clear efficacy against visible light, which is the culprit in EPP (42). Subjects with EPP commonly rely on broad-spectrum sunscreens with SPF of 30 or higher. Conventional SPF, however, is not informative on the protective efficacy in the visible radiation and especially around $408 \mathrm{~nm}$, where protoporphyrin IX has its highest peak of absorption. For this reason, PPF was previously introduced as an index independent of SPF and PFA.

In 1991, an in vitro study first investigated the protection efficacy in UV-A and visible wavelengths of an inorganic filter with $20 \%$ zinc oxide combined with pigmented iron oxide (43).

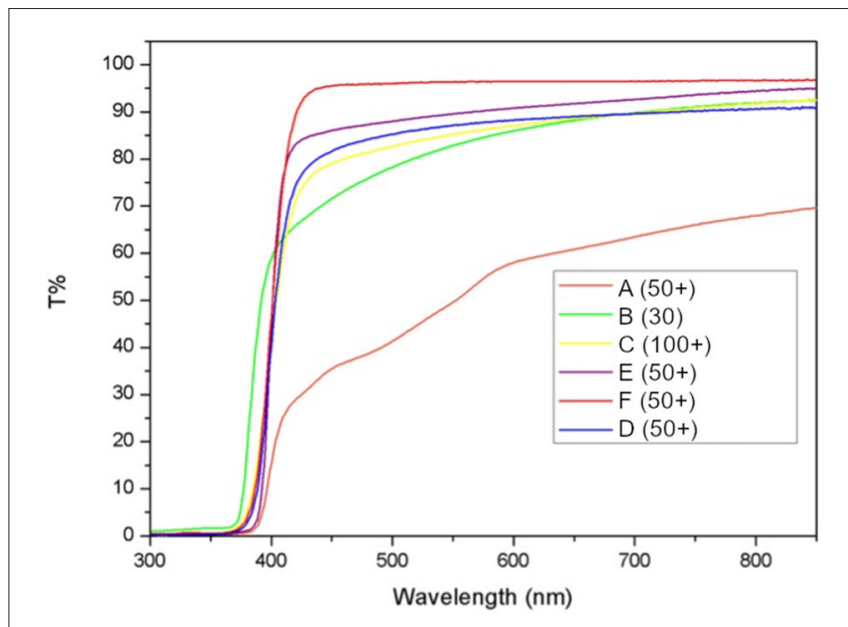

FIGURE 2 | Measured transmittance for each of the six tested products. Transmittance of substrates is calculated as percent of the baseline transmittance of each PMMA plate before sample application (T\%).

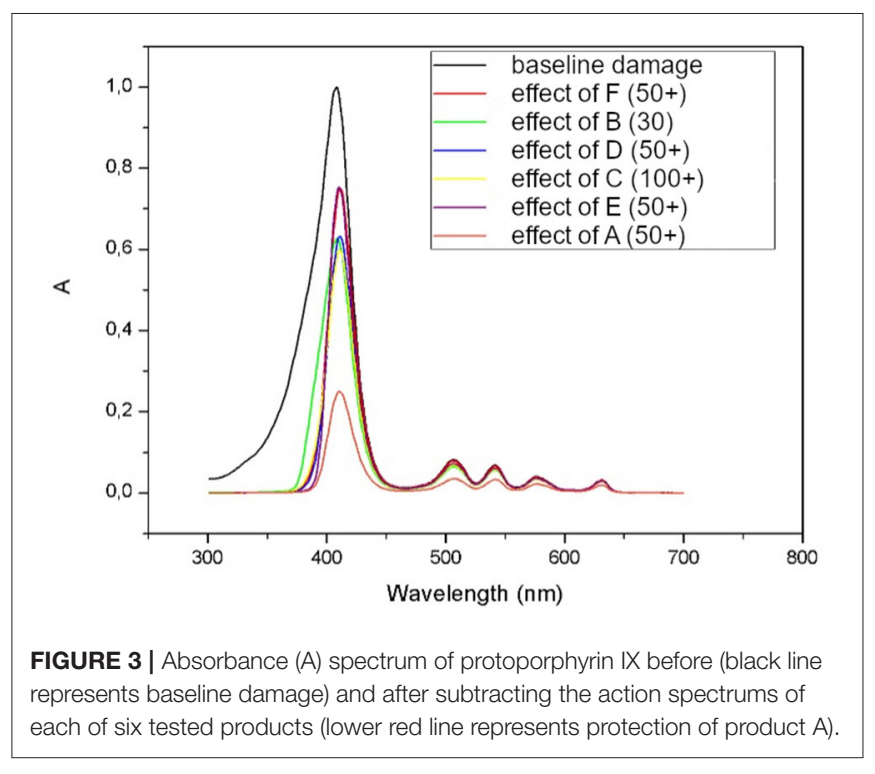

A later study proposed a photosensitivity protection factor, based on the conventional SPF formula adjusted to include wavelengths up to $600 \mathrm{~nm}$, to assess inorganic filters containing $4 \%$ titanium dioxide and 5\% zinc oxide (42). In 2017, Teramura et al. further adapted this index and introduced PPF calculated in the spectral range of 300-450 nm, which is most harmful for individuals with EPP. The authors demonstrated high PPF values in a make-up base emulsion and liquid and powder foundations containing colored and absorbing pigment iron oxide (27). Moreover, the products were tested for 6 months in EPP patients showing efficacy over $78 \%$ and no adverse reactions (27).

The photoprotective products tested in this study include organic and inorganic filters devised to shield UV-B and UV-A radiations, that are the main culprits of erythema in generally healthy subjects and show transmittance close to $0 \%$ 
in these wavelengths. Protection is inefficient in the visible, with transmittance for products B-F between 75 and $95 \%$ at $500 \mathrm{~nm}$. On the other side, product A transmitted $<40 \%$ of radiation at the same frequency (Figure 2).

Our preliminary results show that product A has the highest PPF among tested products with a median value of 4.22. Product A is a sunscreen containing multiple organic UV filters, inorganic filter titanium dioxide and synthetic iron oxides. The latter are colored pigments that absorb radiation in the range $300-700 \mathrm{~nm}$ and, together with inorganic filters titanium dioxide and zinc oxide, justify the performance of this sunscreen (44). Product B scored a poor PPF attributed to micronization-declared by the manufacturer-of inorganic filters zinc oxide and titanium dioxide that shifts protection away from visible wavelengths and toward UV-B and UV-A (45).

The main limitation to the present study is the absence of a proper skin surrogate; though PMMA is a widely used substrate, transmittance measures can be affected by uneven sample distribution and porosity on the material's surface. The authors prepared five samples of each product to improve reproducibility of PPF. According to the preliminary results of this study, a sunscreen containing organic and inorganic filters with pigmented iron oxides, such as product A, showed the highest PPF, with a median of 4,22 among photoprotective products tested in vitro (Figure 3).

\section{REFERENCES}

1. Bottomley SS, Tanaka M, Everett MA. Diminished erythroid ferrochelatase activity in protoporphyria. J Lab Clin Med. (1975) 86:126-31.

2. Bonkowsky HL, Bloomer JR, Ebert PS, Mahoney MJ. Heme synthetase deficiency in human protoporphyria. Demonstration of the defect in liver and cultured skin fibroblasts. J Clin Invest. (1975) 56:1139-48. doi: 10.1172/JCI108189

3. Yien YY, Ducamp S, Van Der Vorm LN, Kardon JR, Manceau H, Kannengiesser C, et al. Mutation in human CLPX elevates levels of $\delta$-aminolevulinate synthase and protoporphyrin IX to promote erythropoietic protoporphyria. Proc Natl Acad Sci USA. (2017) 114:E8045-52. doi: 10.1073/pnas.1700632114

4. Sarkany RPE, Ross G, Willis F. Acquired erythropoietic protoporphyria as a result of myelodysplasia causing loss of chromosome 18. Br J Dermatol. (2006) 155:464-6. doi: 10.1111/j.1365-2133.2006.07318.x

5. Goodwin RG, Kell WJ, Laidler P, Long CC, Whatley SD, McKinley $\mathrm{M}$, et al. Photosensitivity and acute liver injury in myeloproliferative disorder secondary to late-onset protoporphyria caused by deletion of a ferrochelatase gene in hematopoietic cells. Blood. (2006) 107:602. doi: 10.1182/blood-2004-12-4939

6. Gouya L, Puy H, Robreau AM, Bourgeois M, Lamoril J, Da Silva V, et al. The penetrance of dominant erythropoietic protoporphyria is modulated by expression of wildtype FECH. Nat Genet. (2002) 30:27-8. doi: 10.1038/ng809

7. Piomelli S, Lamola AA, Poh Fitzpatrick MB, Seaman C, Harber LC. Erythropoietic protoporphyria and lead intoxication: the molecular basis for difference in cutaneous photosensitivity. I Different rates of disappearance of protoporphyrin from the erythrocytes, both in vivo and in vitro. J Clin Invest. (1975) 56:1519-27. doi: 10.1172/JCI1 08233

8. Lamola AA, Piomelli S, Poh-Fitzpatrick MG, Yamane T, Harber LC. Erythropoietic protoporphyria and lead intoxication: the molecular basis for difference in cutaneous photosensitivity. II Different binding of erythrocyte protoporphyrin to hemoglobin. J Clin Invest. (1975) 56:152835. doi: 10.1172/JCI108234
In conclusion, PPF is indicative of sunscreen protection in vitro and could help patients with EPP, as well as those with other disorders of photosensitivity, identify products tailored on their specific needs (45). Effective protection in real life requires correct use of sunscreens with reapplication of product every $2 \mathrm{~h}$ of sun exposure. Finally, future research in skin pharmacology could provide filters that significantly absorb visible radiation while improving cosmetical tolerability for patients.

\section{DATA AVAILABILITY STATEMENT}

The raw data supporting the conclusions of this article will be made available by the authors without undue reservation.

\section{AUTHOR CONTRIBUTIONS}

AS was responsible for writing the original draft and for visualization. EC was responsible for investigation and for writing the original draft. MP was responsible for project administration and investigation. ET was responsible for methodology and investigation. AN was responsible for investigation and formal analysis. GV was responsible for investigation and for writing the original draft. MA was responsible for conceptualization and supervision. All authors contributed to review and editing of the manuscript.

9. Sandberg S, Talstad I, Høvding G, Bjelland N. Light-induced release of protoporphyrin, but not of zinc protoporphyrin, from erythrocytes in a patient with greatly elevated erythrocyte protoporphyrin. Blood. (1983) 62:846-51. doi: 10.1182/blood.V62.4.846.846

10. Sandberg S, Brun A. Light-induced protoporphyrin release from erythrocytes in erythropoietic protoporphyria. J Clin Invest. (1982) 70:693-8. doi: 10.1172/JCI110664

11. Sassaroli $M$, da Costa $R$, Väänänen $H$, Eisinger J, Poh-Fitzpatrick MB. Distribution of erythrocyte free porphyrin content in erythropoietic protoporphyria. J Lab Clin Med. (1992) 120:614-23.

12. Sandberg S, Romslo I. Porphyrin-induced photodamage at the cellular and the subcellular level as related to the solubility of the porphyrin. Clin Chim Acta. (1981) 109:193-201. doi: 10.1016/0009-8981(81)90334-X

13. Elder GH, Smith SG, Smyth SJ. Laboratory Investigation of the Porphyrias. Ann Clin Biochem. (1990) 27:395-412. doi: 10.1177/000456329002700501

14. Holme SA, Anstey A V, Finlay AY, Elder GH. Badminton MN. Erythropoietic protoporphyria in the UK: Clinical features and effect on quality of life. $\mathrm{Br} \mathrm{J}$ Dermatol. (2006) 155:574-81. doi: 10.1111/j.1365-2133.2006.07472.x

15. McGuire BM, Bonkovsky HL, Carithers RL, Chung RT, Goldstein LI, Lake JR, et al. Liver transplantation for erythropoietic protoporphyria liver disease. Liver Transplant. (2005) 11:1590-6. doi: 10.1002/lt.20620

16. Lala SM, Naik H, Balwani M. Diagnostic delay in erythropoietic protoporphyria. J Pediatr. (2018) 202:3203.e2. doi: 10.1016/j.jpeds.2018.06.001

17. Schmidt H. Erythropoietic protoporphyria. A clinical study based on 29 cases in 14 families. Arch Dermatol. (1974) 110:58-64. doi: 10.1001/archderm.1974.01630070026004

18. Bopp C, Bakos L, Da Graça Busko M. Erythropoietic protoporphyria. Int J Biochem. (1980) 12:909-13. doi: 10.1016/0020-711X(80)90184-6

19. Baart de. la Faille H, Bijlmer-Iest JC, van Hattum J, Koningsberger J, Rademakers LH, van Weelden H. Erythropoietic protoporphyria: clinical aspects with emphasis on the skin. Curr Probl Dermatol. (1991) 20:12334. doi: $10.1159 / 000420016$

20. Biba E. Protection: the sunscreen pill. Nature. (2014) 515:S1245. doi: $10.1038 / 515 S 124 a$ 
21. Langendonk JG, Balwani M, Anderson KE, Bonkovsky HL, Anstey A V, Bissell DM, et al. Afamelanotide for Erythropoietic Protoporphyria. N Engl J Med. (2015) 373:48-59. doi: 10.1056/NEJMoa1411481

22. Scenesse | European Medicines Agency. Available at: https://www.ema. europa.eu/en/medicines/human/EPAR/scenesse (accessed February 10, 2021).

23. Minder EI, Schneider-Yin X, Steurer J, Bachmann LM, A. systematic review of treatment options for dermal photosensitivity in erythropoietic protoporphyria. Cell Mol Biol (Noisy-le-grand). (2009) 55:84-97.

24. Santoro FA, Lim HW. Update on photodermatoses. Semin Cutan Med Surg. (2011) 30:229-38. doi: 10.1016/j.sder.2011.07.007

25. Corbett MF, Herxheimer A, Magnus IA, Ramsay CA, Kobza-Black A. The long term treatment with B-carotene in erythropoietic protoporphyria: a controlled trial. Br J Dermatol. (1977) 97:65562. doi: 10.1111/j.1365-2133.1977.tb14273.x

26. Myrzakhmetov B, Arnoux P, Mordon S, Acherar S, Tsoy I, Frochot C. Photophysical Properties of Protoporphyrin IX, Pyropheophorbide-a and Photofrin (B) in Different Conditions. Pharmaceuticals. (2021) 14:121. doi: $10.3390 /$ ph14020138

27. Teramura T, Mizuno M, Asano H, Naru E, Kawara S, Kamide R, et al. Prevention of photosensitivity with action spectrum adjusted protection for erythropoietic protoporphyria. J Dermatol. (2018) 45:1459. doi: 10.1111/1346-8138.14175

28. Matts PJ, Alard V, Brown MW, Ferrero L, Gers-Barlag H, Issachar N, et al. The COLIPA in vitro UVA method: A standard and reproducible measure of sunscreen UVA protection. Int J Cosmet Sci. (2010) 32:3546. doi: 10.1111/j.1468-2494.2009.00542.x

29. Heinrich U, Tronnier H, Kockott D, Kuckuk R, Heise HM. Comparison of sun protection factors determined by an in vivo and different in vitro methodologies: a study with 58 different commercially available sunscreen products. Int J Cosmet Sci. (2004) 26:79-89. doi: 10.1111/j.0412-5463.2004.00207.x

30. Garoli D, Pelizzo MG, Nicolosi P, Peserico A, Tonin E, Alaibac M. Effectiveness of different substrate materials for in vitro sunscreen tests. $J$ Dermatol Sci. (2009) 56:89-98. doi: 10.1016/j.jdermsci.2009.07.015

31. Garoli D, Pelizzo MG, Bernardini B, Nicolosi P, Alaibac M. Sunscreen tests: correspondence between in vitro data and values reported by the manufacturers. J Dermatol Sci. (2008) 52:193-204. doi: 10.1016/j.jdermsci.2008.06.010

32. International Electrotechinal Commission. IEC 60904-3 (Edition 2.0). Photovoltaic devices-Part 3: Measurement principles for terrestrial photovoltaic (PV) solar devices with reference spectral irradiance data 2008 (2008).

33. Lim HW, Poh-Fitzpatrick MB, Gigli I. Activation of the complement system in patients with porphyrias after irradiation in vivo. J Clin Invest. (1984) 74:1961-5. doi: 10.1172/JCI111616

34. De Goeij AFPM, Van Steveninck J. Photodynamic effects of protoporphyrin on cholesterol and unsaturated fatty acids in erythrocyte membranes in protoporphyria and in normal red blood cells. Clin Chim Acta. (1976) 68:115-22. doi: 10.1016/0009-8981(76)9 0410-1
35. Poh-Fitzpatrick MB. Molecular and cellular mechanisms of porphyrin photosensitization. Photodermatol. (1986) 3:148-57.

36. Ramanujam VMS, Anderson KE. Porphyria diagnostics-part 1: a brief overview of the porphyrias. Curr Protoc Hum Genet. (2015) 2015:17.20.117.20.26. doi: 10.1002/0471142905.hg1720s86

37. Harper $\mathrm{P}, \mathrm{W}$ ahlin $\mathrm{S}$. Treatment options in acute porphyria, porphyria cutanea tarda, and erythropoietic protoporphyria. Curr Treat Options Gastroenterol. (2007) 10:444-55. doi: 10.1007/s11938-007-0044-9

38. Thunell S, Harper P, Brun A. Porphyrins, porphyrin metabolism and porphyrias. IV Pathophysiology of erythyropoietic protoporphyriadiagnosis, care and monitoring of the patient. Scand J Clin Lab Invest. (2000) 60:581-604. doi: 10.1080/003655100448347

39. Schulenburg-Brand D, Katugampola R, Anstey A V, Badminton MN. The cutaneous porphyrias. Dermatol Clin. (2014) 32:36984. doi: 10.1016/j.det.2014.03.001

40. Kutlubay Z, Sevim A, Engin B, Tüzün Y. Photodermatoses, including phototoxic and photoallergic reactions (internal and external). Clin Dermatol. (2014) 32:73-9. doi: 10.1016/j.clindermatol.2013.05.027

41. Maier T, Korting HC. Sunscreens-which and what for? Skin Pharmacol Physiol. (2005) 18:253-62. doi: 10.1159/000087606

42. Moseley H, Cameron H, MacLeod T, Clark C, Dawe R, Ferguson J. New sunscreens confer improved protection for photosensitive patients in the blue light region. Br J Dermatol. (2001) 145:78994. doi: 10.1046/j.1365-2133.2001.04429.x

43. Kaye ET, Levin JA, Blank IH, Arndt KA, Anderson RR. Efficiency of opaque photoprotective agents in the visible light range. Arch Dermatol. (1991) 127:351-5. doi: 10.1001/archderm.1991.01680030071009

44. Latha MS, Martis J, Shobha V, Sham Shinde R, Bangera S, Krishnankutty B, et al. Sunscreening agents: a review. J Clin Aesthet Dermatol. (2013) 6:16-26.

45. Gozali MV, Zhou B-R, Luo D. Update on treatment of photodermatosis. Dermatol Online J. (2016) 22:13030/qt1rx7d228. doi: 10.5070/D3222030080

Conflict of Interest: The authors declare that the research was conducted in the absence of any commercial or financial relationships that could be construed as a potential conflict of interest.

Publisher's Note: All claims expressed in this article are solely those of the authors and do not necessarily represent those of their affiliated organizations, or those of the publisher, the editors and the reviewers. Any product that may be evaluated in this article, or claim that may be made by its manufacturer, is not guaranteed or endorsed by the publisher.

Copyright (C) 2021 Sernicola, Cama, Pelizzo, Tessarolo, Nicolli, Viero and Alaibac. This is an open-access article distributed under the terms of the Creative Commons Attribution License (CC BY). The use, distribution or reproduction in other forums is permitted, provided the original author(s) and the copyright owner(s) are credited and that the original publication in this journal is cited, in accordance with accepted academic practice. No use, distribution or reproduction is permitted which does not comply with these terms. 